\title{
Katell Colin, Le roman-monde d'Édouard Glissant. Totalisation et tautologie
}

\section{Luigia Pattano}

\section{Q OpenEdition}

1 Journals

\section{Edizione digitale}

URL: http://journals.openedition.org/studifrancesi/7750

DOI: 10.4000/studifrancesi.7750

ISSN: 2421-5856

\section{Editore}

Rosenberg \& Sellier

\section{Edizione cartacea}

Data di pubblicazione: 1 décembre 2009

Paginazione: 679

ISSN: 0039-2944

\section{Notizia bibliografica digitale}

Luigia Pattano, «Katell Colin, Le roman-monde d'Édouard Glissant. Totalisation et tautologie», Studi

Francesi [Online], 159 (LIII | III) | 2009, online dal 30 novembre 2015, consultato il 09 janvier 2021. URL: http://journals.openedition.org/studifrancesi/7750 ; DOI: https://doi.org/10.4000/studifrancesi.7750

Questo documento è stato generato automaticamente il 9 janvier 2021.

\section{(c) (i) $\odot$}

Studi Francesi è distribuita con Licenza Creative Commons Attribuzione - Non commerciale - Non opere derivate 4.0 Internazionale. 


\title{
Katell Colin, Le roman-monde d'Édouard Glissant. Totalisation et tautologie
}

\author{
Luigia Pattano
}

\section{NOTIZIA}

KATELL COLIN, Le roman-monde d'Édouard Glissant. Totalisation et tautologie, Québec, Les Presses de l'Université de Laval, 2008, pp. 311.

1 Versione rivista e rielaborata della tesi di dottorato sostenuta nel maggio 2006 presso l'Université Laval della città di Québec, il saggio di Katell Colin ha sicuramente il pregio di azzardare una lettura critica globale dell'opera di Édouard Glissant, una lettura che si vuole libera, nella misura del possibile, dal peso e dall'influenza di un autore che, grazie a indiscusse doti seduttive è riuscito, secondo l'autrice, a conquistarsi un posto di primo piano in seno all'istituzione letteraria francese (e non solo). Abbagliata da un discorso nuovo e affascinante nella sua pretesa oscurità, la critica glissantiana avrebbe abbracciato generalmente con entusiasmo la poetica dell'autore specializzandosi nell'arte del panegirico o, nella migliore delle ipotesi, della semplice parafrasi. Pratiche che la colin giustamente sconfessa dichiarando di voler interrogare l'opera letteraria di un grande autore - di cui non mette in discussione il valore ma talvolta la buona fede a partire dai soli testi narrativi, letti in un'ottica socio-pragmatica.

2 Facendo convergere due discipline apparentemente distanti tra loro come la sociologia e la pragmatica, la studiosa intende dimostrare l'esistenza di un nesso tra lo statuto sociale dello scrittore martinicano e le pratiche discorsive messe in luce dall'analisi pragmatica degli enunciati: "Lecture intertextuelle du monde, écrite par des recoupements, des digressions et des régénérations thématiques si nombreuses qu'elle semble traduire avant tout la volonté de porter le monde entier sur une tête d'épingle» (p. 13). Il corpus preso in esame (che coincide con l'intera produzione narrativa di 
Glissant) rappresenta un tentativo grandioso, ma non certo inedito secondo la studiosa, di rifondare il mondo. Per la colin, la specificità del progetto glissantiano non risiede tanto nella sua ambizione demiurgica quanto nella volontà dissimulata di imporre al lettore il senso da attribuire all'opera. L'analisi delle strategie attraverso le quali l'autore mette in atto il proprio progetto porta la studiosa ad affermare che nel caso di Glissant non soltanto l'opera contiene il proprio metatesto, ma è essa stessa metatesto, discorso sul discorso, quindi massimamente autoreferenziale. Il ricorso alla sociologia si spiega dunque come il tentativo di cercare fuori dai testi le ragioni di un disegno che risulta totalizzante sebbene rifiuti continuamente l'ideologia «totalitaria», per riprendere i termini dello stesso Glissant, dissimulata in ogni discorso di sistema che pretende di abbracciare e spiegare la totalità. $\mathrm{E}$ qui sta, a nostro avviso, il principale punto debole dell'analisi della colin che legge, con un tono che non può che risultare polemico, l'attività letteraria di Glissant come un'impresa mossa da un'enorme volontà di potenza il cui fine principale consisterebbe nell'autolegittimazione. Tale interpretazione reca in sé in maniera implicita un'evidente impronta psicoanalitica che porta la ricercatrice a dipingere il progetto letterario avviato nel 1958 con La Lézarde e giunto di fatto a compimento con la pubblicazione, nel 1993, di Tout-Monde da un lato come un'operazione compensatoria di fronte a un reale deludente e dall'altro come un tentativo di rivalsa da parte di un individuo soggetto a una serie di dominazioni sia in ambito politico che letterario.

3 Tuttavia, benché la colin giunga a conclusioni discutibili sulle finalità dell'opera, la sua analisi dei testi e le obiezioni che muove a Glissant e alla critica compiacente sono spesso pertinenti e condivisibili. Particolarmente efficace risulta la visione d'insieme che emerge dalla lettura ideologica della produzione letteraria glissantiana, frutto del percorso dell'autore, che passa da una poetica dell'antillanità, volta a contribuire alla costruzione della nazione martinicana e alla legittimazione del suo popolo, a una poetica della Relazione, che erge le popolazioni insediate nel bacino dei Caraibi a modello di un nuovo tipo di civiltà caratterizzato dalla creolizzazione. 